\title{
Modified Harada-Ito Procedure in Acquired Superior Oblique Palsy with Exotropia
}

\author{
Sangeetha Tharmathurai', Ahmad Tajudin Liza-Sharmini', Qamaruddin Fazilawati² \\ ${ }^{1}$ Department of Ophthalmology, School of Medical Sciences, Universiti Sains Malaysia, Health Campus, Kubang Kerian, Malaysia \\ ${ }^{2}$ Department of Ophthalmology, Hospital Tengku Ampuan Rahimah, Klang, Malaysia \\ Email: sangt@hotmail.com
}

How to cite this paper: Tharmathurai, S., Liza-Sharmini, A.T. and Fazilawati, Q. (2016) Modified Harada-Ito Procedure in Acquired Superior Oblique Palsy with Exotropia. Open Journal of Ophthalmology, 6, 205-209. http://dx.doi.org/10.4236/ojoph.2016.64029

Received: September 11, 2016

Accepted: November 6, 2016

Published: November 9, 2016

Copyright $\odot 2016$ by authors and Scientific Research Publishing Inc. This work is licensed under the Creative Commons Attribution International License (CC BY 4.0).

http://creativecommons.org/licenses/by/4.0/

\begin{abstract}
Superior oblique palsy is the most common isolated cranial nerve palsy and is commonly associated with exotropia. Modified Harada-Ito procedure can be used to correct excyclotorsion in symptomatic patients. We report a case of acquired superior oblique palsy with exotropia undergoing modified Harada-Ito procedure. A 33 years old man presented with torsional diplopia. On examination there was 10 degrees of left excyclotorsion on double Maddox rod with 25-diopter of exotropia on primary gaze and 20-diopter on lateral gaze suggestive of lateral incomitancy. He underwent a Fells modification of Harada-Ito procedure with bilateral rectus recession. Three months postoperative, he was orthophoric. Modified Harada-Ito procedure is a successful procedure in overcoming torsional diplopia. It is important to identify lateral incomitancy to prevent overcorrection of the horizontal deviation.
\end{abstract}

\section{Keywords}

Modified Harada-Ito, Superior Oblique Palsy, Exotropia, Strabismus

\section{Introduction}

Symptomatic diplopia can be very debilitating to the patient. It can interfere with obtaining stable fusion [1]. Harada-Ito procedure was introduced in 1964, to correct excyclotorsion [2]. The original method of correction was to anteriorize the anterior half of the superior oblique tendon without disinsertion [2]. Fells modified this technique in 1974, whereby the anterior half of the tendon was disinserted and moved forward and laterally [3]. Harada-Ito procedure is on the basis that the anterior fibers of the superior oblique contribute to the torsional action while the posterior fibers contribute to the vertical action [4]. The incidence of superior oblique palsy with a horizontal deviation ranges from $36 \%$ to $55.6 \%$ [2]. We report a case of acquired superior oblique palsy with 
exotropia.

\section{Case Report}

A 33 years old man, presented with torsional diplopia worse on primary and downgaze following a motor vehicle accident. On examination, his visual acuity was $6 / 6$ both eyes. There was presence of left hypertropia and left alternating exotropia at 30 diopters at near, 25 diopters at far and 20 diopters on lateral gaze (Figure 1). Bielschowsky 3-step test was positive. Double Maddox rod showed a 10-degree of left excylotorsion in primary and downgaze. He underwent a right Fells modification of Harada-Ito procedure with bilateral lateral rectus recession.

A conjunctival peritomy was done at the superior temporal area and the superior rectus muscle was identified and retracted to identify the superior oblique muscle tendon. A longitudinal tendon split was performed extending $8 \mathrm{~mm}$ and Vicryl $6 / 0$ was woven through the tendon. The lateral rectus muscle was then identified and isolated. The anterior half of the superior oblique muscle tendon was sutured with Vicryl 6/0, 8 $\mathrm{mm}$ posterior to the lateral rectus muscle. The lateral rectus muscle was subsequently recessed $5 \mathrm{~mm}$.

Intraoperatively, it was noted that his superior oblique was atrophied. He recovered well and was orthophoric with no postoperative diplopia 3 months post surgery (Figure 2).

\section{Discussion}

Unilateral and bilateral superior oblique palsy can be associated with horizontal deviation and is commonly seen with exotropia [5] [6]. Torsional diplopia poses significant surgical challenge to the surgeon and patient. Harada-Ito procedure is able to address the problem of excyclotorsion.

Our patient underwent the Fells modification of Harada-Ito procedure together with lateral rectus recession to correct his incyclotorsion as well as exotropia. In our case it
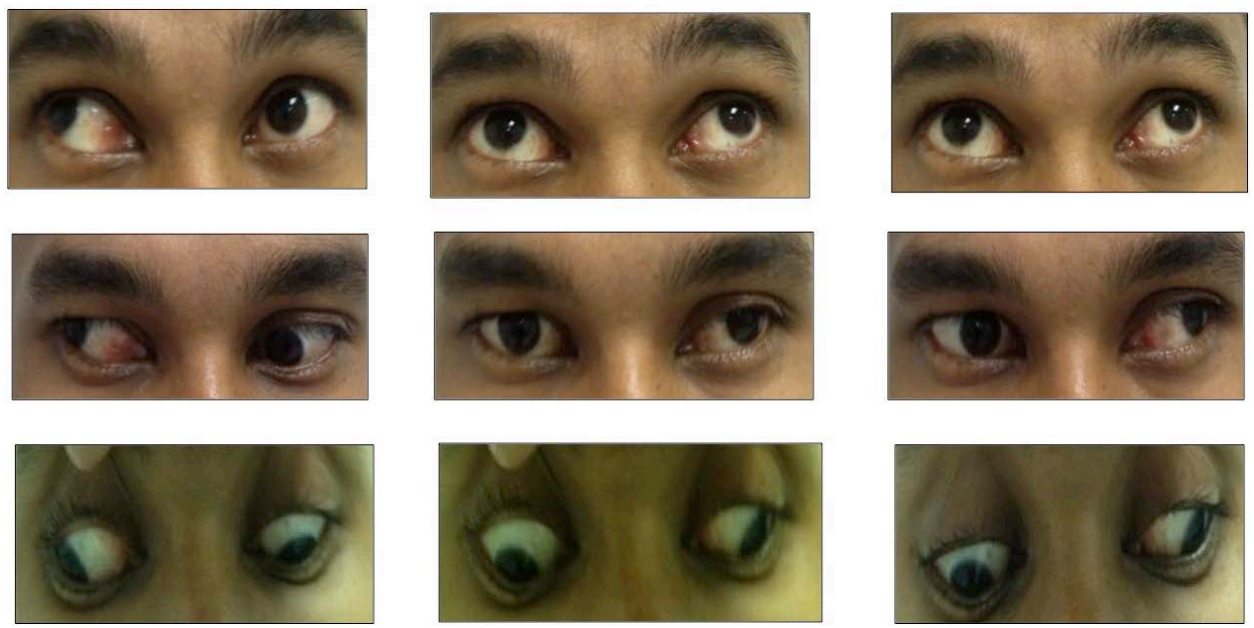

Figure 1. Preoperative picture showing left hypertropia and exotropia. 

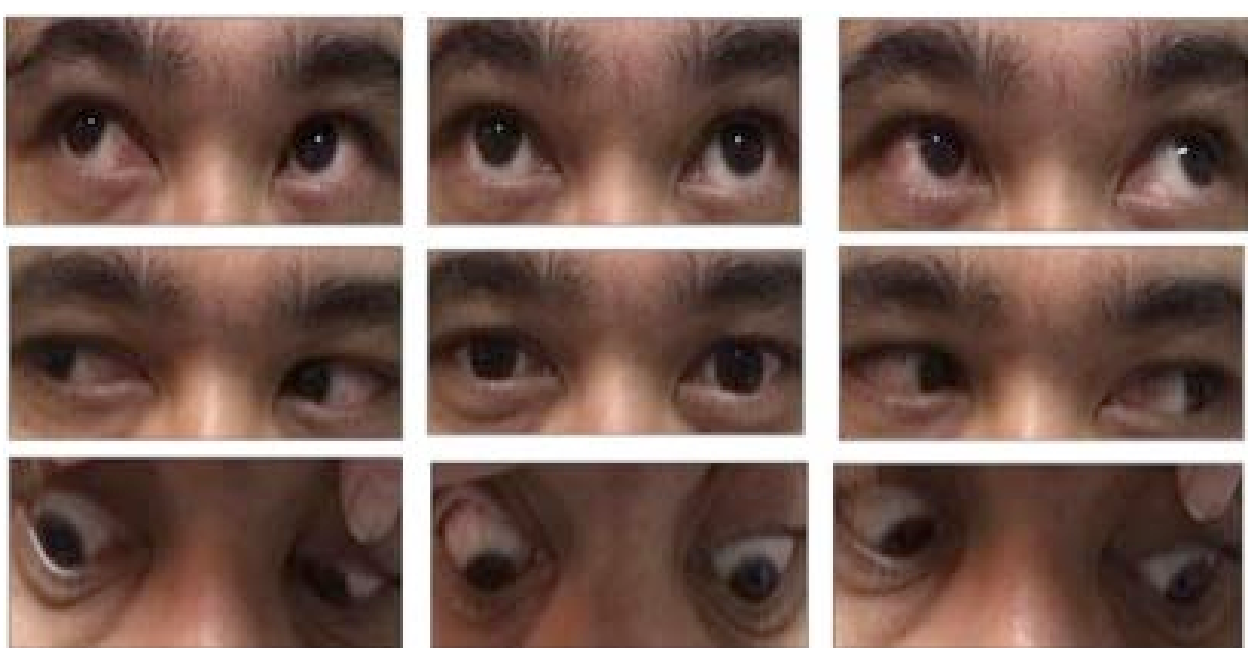

Figure 2. Three months postoperative showing orthophoric at primary gaze.

was important to identify the existence of lateral incomitancy; which is a smaller exodeviation in the lateral gaze though the abduction is full. Lateral incomitancy is more common in patients with superior oblique palsy as the abducting power of the superior oblique is reduced [7]. It has been reported that the incidence of superior oblique palsy with horizontal deviation ranges from $36 \%$ to $55.6 \%$ [8] [9]. We found that our patient had a smaller deviation (20 diopters) on his lateral gaze. In cases with lateral incomitancy, there is tendency to overcorrect or undercorrect the amount of lateral rectus muscle recessed.

Lee et al. [7] in their study to evaluate surgical normogram for lateral rectus recession in patients undergoing inferior oblique recession for superior oblique palsy found that reducing the amount of lateral rectus recession by 1 to $2 \mathrm{~mm}$ was a successful method to prevent overcorrection. Moore et al. [9] found that $20 \%$ or more reduction of exodevation in lateral gaze may be overcorrected if the measurements are solely based on primary gaze measurements.

Helveston et al. [5] found that in cases with minimal exodeviation, correction of the torsional component only is adequate. Study by Lee et al. [7] noted that large angle deviation between 20.4 to 26.4 diopters should be corrected with combined horizontal muscle surgery. Our patient had an exodcviation of 25 diopter at far and thus bilateral lateral rectus recession was done together with the correction of the torsional component. We reduced the amount of lateral rectus recession by $1 \mathrm{~mm}$, that is $5 \mathrm{~mm}$ and found that the patient was orthophoric post operatively.

We performed the Fells modification of Harada-Ito procedure on our patient using non adjustable suture. A study by Fells [3] found that though Harada-Ito was an effective method to correct excyclotorsion; disinserting the muscle was most useful for correction of extorsion in downgaze.

A study by Nishimura et al. [10] found that the adjustable Harada-Ito was a successful surgery and only $8 \%$ of patients had a regression between 2 to 12 months post surgery. This was attributed to the failure of loosening of the antagonist muscle. However, 
there have been other postulations as to the cause of regression due to loosening of scleral suture and incomplete healing process between the sclera and the superior oblique tendon [11]. Another study by Bradfield et al. [12] found that all patients who had 10 degrees or below of torsion preoperatively obtained surgical success after the modified Harada-Ito procedure. Their study also found that the mean torsion correction with the Harada-Ito procedure was 10.3 degrees (95\% CI, 8.3 - 12.4). In our patient the degree of excyclotorsion was 10 degrees but the follow up period was only for 3 months and hence a longer study period is needed to determine the longterm success of the surgery. Intraoperatively, we found that the superior oblique muscle was atrophied. Though atrophied muscle is mainly seen in congenital superior oblique palsy; long standing acquired superior oblique palsy shows a similar picture [13]. This is due to denervation atrophy [14] resulting from loss up to $80 \%$ of muscle bulk because of wasting of individual muscle fibers [15].

\section{Conclusion}

Fells modification of Harada-Ito surgery is a successful procedure in overcoming torsional diplopia. It is important to evaluate the presence of lateral incomitancy in patients with associated horizontal deviations to prevent overcorrection.

\section{Statement of Consent}

The patient has given full consent for publication of this case report.

\section{References}

[1] Mitchell, P.R. and Parks, M.M. (1992) Surgery for Bilateral Superior Oblique Palsy. Ophthalmology, 89, 484-488. http://dx.doi.org/10.1016/S0161-6420(82)34765-X

[2] Harada, M. and Ito, Y. (1964) Surgical Correction of Cyclotropia. Japan Journal Ophthalmology, 8, 88-96.

[3] Fells, P. (1974) Management of Paralytic Strabismus. British Journal Ophthalmology, 58, 255-265. http://dx.doi.org/10.1136/bjo.58.3.255

[4] Fink, W.H. (1951) Surgery of the Oblique Muscles of the Eye. St Louis, Mosby.

[5] Helveston, E.M., Mora, J.S., Lipsky, S.N., et al. (1996) Surgical Treatment of Superior Oblique Palsy. Transactions of the American Ophthalmological Society, 94, 315-328.

[6] Davis, G.T. (1971) Vertical Deviations Associated with Exodeviations. In: Manley, D.R., Ed., Symposium on Horizontal Ocular Deviations, CV Mosby, St. Louis, 149-156.

[7] Lee, J.Y., Kim, S.H., Yi, S.T., Lee, T.E. and Cho, Y.A. (2012) Contemplation of the Surgical Normoagram of Lateral Rectus Recession for Exotropia Associated with Superior Oblique Palsy. Korean Journal Ophthalmology, 26, 195-198. http://dx.doi.org/10.3341/kjo.2012.26.3.195

[8] Knapp, P. (1971) Management of Exotropia. In: Burian, H.M., New Orleans Academy of Ophthalmology, Eds., Symposium on Strabismus. Transactions of the New Orleans Academy of Ophthalmology, CV Mosby, St Louis, 233.

[9] Moore, S. (1969) The Prognostic Value of Lateral Gaze Measurement in Intermittent Exotropias. American Orthoptic Journal, 19, 69. 
[10] Nishimura, J.K. and Rosenbaum, A.L. (2002) The Long Term Torsion Effect of the Adjustable Harada-Ito Procedure. Journal of American Association for Pediatric Ophthalmology and Strabismus, 6, 141-144. http://dx.doi.org/10.1067/mpa.2002.123429

[11] Von Noorden, G.K. (1979) Clinical Observations in Cyclodeviations. Ophthalmology, 86, 1451-1461. http://dx.doi.org/10.1016/S0161-6420(79)35376-3

[12] Bradfield, Y.S., Struck, M.C., Kushner, B.J., Neely, D.E., Plager, D.A. and Gangnon, R.E. (2012) Outcomes of Harada-Ito Surgery for Acquired Torsional Diplopia. Journal of American Association for Pediatric Ophthalmology and Strabismus, 16, 453-457. http://dx.doi.org/10.1016/j.jaapos.2012.06.007

[13] Sato, M., Yagasaki, T., Kora, T. and Awaya, S. (1998) Comparison of Muscle Volume between Congenital and Acquired Superior Oblique Palsy by Magnetic Resonance Imaging. Japan Journal Ophthalmology, 42, 466-470. http://dx.doi.org/10.1016/S0021-5155(98)00044-6

[14] Horon, J.C., Tsai, R.K., Truwit, C.I. and Hoyt, W.F. (1990) Magnetic Resonance Imaging of Superior Oblique Muscle Atrophy in Acquired Trochlea Nerve Palsy. American Journal of Ophthalmology, 110, 315-316. http://dx.doi.org/10.1016/S0002-9394(14)76358-5

[15] Kakulas, B. and Adams, R.D. (1985) Disease of Muscle. Harper \& Row, Philadelphia, 129-158.

Submit or recommend next manuscript to SCIRP and we will provide best service for you:

Accepting pre-submission inquiries through Email, Facebook, LinkedIn, Twitter, etc.

A wide selection of journals (inclusive of 9 subjects, more than 200 journals)

Providing 24-hour high-quality service

User-friendly online submission system

Fair and swift peer-review system

Efficient typesetting and proofreading procedure

Display of the result of downloads and visits, as well as the number of cited articles

Maximum dissemination of your research work

Submit your manuscript at: http://papersubmission.scirp.org/

Or contact ojoph@scirp.org 